\title{
Transcerebellar diameter: an effective tool in predicting gestational age in normal and IUGR pregnancy
}

\author{
Sunita Dashottar ${ }^{1}$, Krishna Pratap Singh Senger ${ }^{2 *}$, Yashashvi Shukla ${ }^{1}$, \\ Ankita Singh ${ }^{3}$, Surabhi Sharma ${ }^{4}$
}

\begin{abstract}
${ }^{1}$ Department of Radiology, Command Hospital, Lucknow, Uttar Pradesh, India
${ }^{2}$ Deptartment of Radiodiagnosis, Army Hospital, Research and Referral, New Delhi, India

${ }^{3}$ BMGF, New Delhi, India

${ }^{4}$ Department of Radiodiagnosis, Command Hospital, Lucknow, Uttar Pradesh, India.
\end{abstract}

Received: 14 August 2018

Accepted: 06 September 2018

\section{*Correspondence: \\ Dr. Krishna Pratap Singh Senger, \\ E-mail:kpssafmc@yahoo.com}

Copyright: (c) the author(s), publisher and licensee Medip Academy. This is an open-access article distributed under the terms of the Creative Commons Attribution Non-Commercial License, which permits unrestricted non-commercial use, distribution, and reproduction in any medium, provided the original work is properly cited.

\section{ABSTRACT}

Background: Gestational age is the common term used during pregnancy to describe how far advanced is the pregnancy. In the second and third trimesters, estimation of gestational age is accomplished by measuring the biparietal diameter, head circumference, abdominal circumference, and femur length. The transverse cerebellar diameter (TCD) may serve as a reliable predictor of gestational age (GA) of the fetus and a standard against which aberrations in other fetal parameters can be compared.

Methods: The study was conducted in the tertiary care teaching hospital from July 2016 to March 2017. 200 pregnant women of gestational age 15-40 weeks of pregnancy referred from Dept of Obs and Gynae for antenatal scan comprised our study sample.

Results: Age of women ranged from 18 to 43 years with maximum number of patients aged 26-30 years. Maximum cases with clinical suspicion for IUGR were in gestational age >36-40 weeks (50\%). Evaluation of difference in actual and estimated gestational age between normal and actual gestational age showed that for normal pregnancy as well as in IUGR pregnancies mean difference between estimated and actual gestational age was minimum in TCD followed by other established parameters.

Conclusions: TCD being a stable parameter irrespective of growth status of fetus, provides a basis for its usefulness as a ratio to predict IUGR and other perainatal outcomes as used in several studies. Thus, despite not being a direct marker for IUGR it can serve as a surrogate marker for detection of IUGR and another adverse perinatal outcome.

Keywords: Biometry, IUGR, Pregnancy, TCD

\section{INTRODUCTION}

Gestation covers the period the baby has spent in mother's womb or in other words how old the pregnancy is. It is measured in weeks. It begins from the first day of last menstrual period (LMP) to the current date. A fullterm pregnancy may last upto 42 weeks. Pregnancy is monitored objectively in terms of fetal growth as compared to period of gestation for planning mode of delivery, managing complications in midcourse and management of high-risk cases. Accurate estimate of gestational age is vital for determining viability in preterm labour and in post-dated deliveries.

The commonly employed method and the standard of care in monitoring gestation is antenatal ultrasound 
examination. Based on certain fetal parameters the gestational age is calculated and compared with period of gestation to look for fetal growth. The accuracy of gestational age by measuring fetal parameters is maximum in first trimester and accuracy reduces as fetal age advances from second to third trimester. ${ }^{1}$

The commonly employed fetal parameters for estimating gestational age include biparietal diameter (BPD), head circumference (HC), abdominal circumference (AC) and femur length (FL). The accurate measurement of these parameters depends a lot on fetal lie, shape of skull, location of placents, flexion of fetal head and engagement, maternal obesity and multiplicity of gestation. More recently another fetal patameter, trans cerebellar diameter (TCD) has evolved as a promising indicator for assessing fetal growth and gestational age. ${ }^{2,3}$

TCD is an additional parameter over those four basic paramaters. It is calculated by the maximum diameter between the cerebellar hemispheres on axial scan. The value of TCD in millimetres corresponds roughly to the period of gestation between 14-40 weeks.

Another added advantage is its non-variance in cases of intra uterine growth retardation (IUGR). So TCD can be used as an independent parameter against which other established parameters can be compared when gestational age cannot be calculated by LMP. ${ }^{3}$

Till recently BPD was considered as the most consistent parameter in determining gestational age. It is calculated from the outer table of the skull side close to the probe to the inner table of the side farthest from the skull. It is also useful in determining period of gestation in pregnant ladies who are unsure about their POG.

Difficulty arises when such ladies present late in second or third trimester with IUGR. Now even BPD may hold true for such cases when there is no input on LMP. In such scenarios, TCD holds the ground as it is least affected by IUGR, so the POG calculated from TCD can act an internal check for other fetal parameters in establishing IUGR. ${ }^{2,3}$

The accuracy of TCD between 22-28 weeks is 0-2 days, for 29-36 weeks it is within 5 days and at 37 weeks it is within 9 days of actual gestation.

So normograms based on TCD can predict POG with almost accuracy reaching upto $94 \%$ in third trimester. ${ }^{4}$ Keeping all this in picture this study was planned to assess the correlation between TCD and gestational age in normal and IUGR pregnancies.

The aim and objective of the present study were to evaluate the usefulness of transcerebellar diameter as against the conventional parameters of biparietal diameter, abdominal circumference and femur length in normal pregnant mothers between 15 to 40 weeks, to evaluate the usefulness of transcerebellar diameter in antenatal diagnosis of intrauterine growth retardation, to derive normograms for estimating the gestational age of the fetus from the measured transcerebellar diameter.

\section{METHODS}

The study was conducted in the tertiary care teaching hospital from July 2016 to March 2017. Pregnant women of gestational age 15-40 weeks of pregnancy referred from Dept of Obstetrics and Gynae for antenatal scan comprised present study sample. The sampling frame was bound by the following inclusion and exclusion criteria.

\section{Inclusion criteria}

- Normal singleton pregnancies of 15- and 40-weeks' gestation with known last menstrual period.

- Clinically suspected intrauterine growth retardation.

\section{Exclusion criteria}

- Congenital malformations.

- Multiple pregnancies.

No prior approach for sample size calculation was followed and all patients falling in the sampling frame were included in the study.

The power analysis was done post facto. All the patients falling in the sampling frame were invited to participate in the study. The study was conducted on 200 pregnant women (including both normal and IUGR pregnancies). Statistical analysis was done using Statistical Package for Social Sciences version 21.

\section{RESULTS}

The present study was carried out with an aim to assess correlation of Transverse Cerebellar Diameter with Gestational Age in normal and IUGR pregnancy.

The compiled result for the ease of summarizing is enumerated below:

A total of 200 consecutive pregnant women falling in sampling frame were enrolled in the study.

Table 1 shows the age wise distribution of women enrolled in the study. Age of women ranged from 18 to 43 years with maximum number of patients were aged 26-30 years $(n=87 ; 43.5 \%)$ followed by those aged $21-25$ years $(n=77 ; 38.5 \%), 31-35$ years $(n=27 ; 13.5 \%),<20$ years $(n=6 ; 3 \%)$ and 35 years $(n=3 ; 1.5 \%)$. Mean age of women was $26.59+3.79$ years. By statistically dividing the patient population into various age groups, 
Table 1: Correlation of gestational age (by LMP) by estimated gesational age based on different fetal biometric parameters (all pregnancies): biparietal diameter (BPD).

\begin{tabular}{|c|c|c|c|c|c|c|c|c|c|}
\hline \multirow{2}{*}{$\begin{array}{l}\text { Gestational Age } \\
\text { (weeks) by LMP } \\
\text { (weeks) }\end{array}$} & \multicolumn{2}{|c|}{$\begin{array}{l}\text { GA by LMP } \\
\text { (weeks) }\end{array}$} & \multicolumn{2}{|c|}{$\begin{array}{l}\text { GA by BPD } \\
\text { (weeks) }\end{array}$} & \multicolumn{2}{|c|}{$\begin{array}{l}\text { Estimated- } \\
\text { actual (weeks) }\end{array}$} & \multicolumn{2}{|c|}{$\begin{array}{l}\text { Significance of } \\
\text { difference } \\
\text { (paired ' } t \text { '-test) }\end{array}$} & \multirow{2}{*}{$\begin{array}{l}\text { Correlation } \\
\text { between actual } \\
\text { and estimated GA } \\
\text { 'r' }\end{array}$} \\
\hline & Mean & SD & Mean & SD & Mean & SD & ' $t$ ' & 'p' & \\
\hline $16-20(n=47)$ & 18.81 & 0.99 & 18.88 & 1.04 & 0.07 & 0.59 & 0.78 & 0.437 & 0.83 \\
\hline$>20-24(\mathrm{n}=34)$ & 21.42 & 1.32 & 21.26 & 1.55 & -0.16 & 0.87 & -1.10 & 0.279 & 0.83 \\
\hline$>24-28(n=15)$ & 25.94 & 1.16 & 25.83 & 2.26 & -0.11 & 1.45 & -0.30 & 0.766 & 0.83 \\
\hline$>28-32(\mathrm{n}=25)$ & 30.93 & 0.96 & 30.77 & 1.74 & -0.15 & 1.85 & -0.42 & 0.682 & 0.16 \\
\hline$>32-36(\mathrm{n}=67)$ & 33.72 & 0.97 & 33.61 & 1.63 & -0.11 & 1.51 & -0.61 & 0.543 & 0.41 \\
\hline$>36-40(n=12)$ & 37.02 & 0.78 & 35.27 & 1.89 & -1.75 & 1.32 & -4.58 & 0.001 & 0.82 \\
\hline Total & 27.39 & 6.74 & 27.21 & 6.66 & -0.18 & 1.34 & -1.93 & 0.055 & 0.98 \\
\hline
\end{tabular}

Table 2: Correlation of gestational age (by LMP) by estimated gesational age based on different fetal biometric parameters (all pregnancies): composite gestational age (biometry).

\begin{tabular}{|c|c|c|c|c|c|c|c|c|c|}
\hline \multirow{2}{*}{$\begin{array}{l}\text { Gestational age } \\
\text { (weeks) by } \\
\text { LMP (weeks) }\end{array}$} & \multicolumn{2}{|c|}{$\begin{array}{l}\text { GA by LMP } \\
\text { (weeks) }\end{array}$} & \multicolumn{2}{|c|}{$\begin{array}{l}\text { GA by FL } \\
\text { (weeks) }\end{array}$} & \multicolumn{2}{|c|}{$\begin{array}{l}\text { Estimated-actual } \\
\text { (weeks) }\end{array}$} & \multicolumn{2}{|c|}{$\begin{array}{l}\text { Significance of } \\
\text { difference } \\
\text { (Paired 't'-test) }\end{array}$} & \multirow{2}{*}{$\begin{array}{l}\text { Correlation } \\
\text { between actual } \\
\text { and estimated GA } \\
\text { ' } r \text { ' }\end{array}$} \\
\hline & Mean & SD & Mean & SD & Mean & SD & 't' & 'p' & \\
\hline $16-20(n=47)$ & 18.81 & 0.99 & 18.61 & 0.91 & -0.20 & 0.48 & -2.85 & 0.007 & 0.88 \\
\hline$>20-24(\mathrm{n}=34)$ & 21.42 & 1.32 & 20.94 & 1.42 & -0.48 & 0.71 & -3.96 & $<0.001$ & 0.87 \\
\hline$>24-28(n=15)$ & 25.94 & 1.16 & 25.05 & 1.86 & -0.90 & 1.08 & -3.20 & 0.006 & 0.84 \\
\hline$>28-32(\mathrm{n}=25)$ & 30.93 & 0.96 & 30.34 & 1.49 & -0.59 & 1.68 & -1.75 & 0.092 & 0.11 \\
\hline$>32-36(\mathrm{n}=67)$ & 33.72 & 0.97 & 33.05 & 1.28 & -0.67 & 1.09 & -5.05 & $<0.001$ & 0.56 \\
\hline$>36-40(n=12)$ & 37.02 & 0.78 & 35.26 & 1.49 & -1.76 & 0.93 & -6.55 & $<0.001$ & 0.84 \\
\hline Total & 27.39 & 6.74 & 26.79 & 6.53 & -0.60 & 1.06 & -7.99 & $<0.001$ & 0.99 \\
\hline
\end{tabular}

It was known that there was a wide variation in the age of the sample with mean age of about 26 years, adding strength to the authenticity. The sample was further divided as per the week of gestational age (as per LMP or as mentioned in the requisition form). Gestational age of cases ranged from 15 weeks 6 days to 38 weeks 2 days. Maximum number of cases were in gestational age $>32$ 36 weeks $(33.5 \%)$ followed by those in 16-20 weeks $(\mathrm{n}=47 ; 23.5 \%),>20-25$ weeks $(\mathrm{n}=34 ; 17 \%)$ and $>28-32$ weeks $(\mathrm{n}=25 ; 12.5 \%)$ respectively. Cases with gestational age $>24-28$ weeks and $>36-40$ weeks comprised only $7.5 \%$ and $6 \%$ of study population respectively.

This observation was owing to the fact that most of the cases referred to the department were either for the second trimester fetal anomaly scan or for the third trimester scan. Proportion of clinically suspected IUGR cases out of total cases at different gestational age categories ranged from $0 \%$ (16-20 weeks) to $50 \%$ (>3640 weeks). Maximum cases with clinical suspicion for IUGR were in gestational age >36-40 weeks (50\%) followed by $>24-28$ weeks $(26.7 \%)$, >32-36 weeks $(16.4 \%),>28-32$ weeks $(12 \%)$ and $>20-24$ weeks $(5.9 \%)$. None of the cases enrolled between 16-20 weeks were clinically suspected for IUGR. Statistically, there was a significant difference in proportional of clinically suspected IUGR cases at different gestational age groups $(\mathrm{p}<0.001)$. With increasing gestational age, there was a significant increase in TCD values. The correlation between TCD measurements and gestational age was strong at 16-20, >20-24 and >24-28 weeks ( $>0.7)$. It was moderate at $>24-28$ weeks $(r=0.600)$ and mild at $>32-35$ and $>36-40$ weeks ( $r=0.376$ and 0.387 respectively). Overall, there was a strong correlation between TCD and gestational age $(\mathrm{r}=0.984)$. Using linear regression method, the equation derived for estimation of gestational age using TCD as a reference was GA $=0.547 * \mathrm{TCD}+$ 9.231 (Table 3) Evaluation of difference in actual and estimated gestational age between normal and actual gestational age showed that for normal pregnancy, mean difference between estimated and actual gestational age was minimum in TCD $(-0.011 \pm 1.18$ weeks $)$ followed by BPD $(0.09 \pm 1.04$ weeks $)$, AC $(-0.24 \pm 0.78$ weeks $)$, FL ($0.20+0.84$ weeks) and CGA $(-0.34+0.76)$ respectively. Statistically, this difference among groups was significant $(\mathrm{p}<0.001)$. For IUGR pregnancies, the mean difference was maximum for AC $(-2.72+1.70$ weeks $)$ followed by CGA $(-2.36+1.14$ weeks), BPD $(-2.02+1.64$ weeks $)$, FL $(-1.81+1.29$ weeks) and minimum in TCD $(0.04+1.23$ weeks). On comparing the gap between estimated and actual gestational age between normal and actual pregnancies, the difference was found to be significant statistically $(p<0.001)$ for all the estimators except for TCD $(\mathrm{p}=0.828)$. 
Table 3: Comparison of mean TCD at different gestational ages and their correlation with gestational age.

\begin{tabular}{|c|c|c|c|c|}
\hline \multirow{2}{*}{ Gestational age (weeks) } & \multirow{2}{*}{ Total no. } & \multicolumn{2}{|l|}{ TCD } & \multirow{2}{*}{ Correlation ' $r$ ' } \\
\hline & & Mean & SD & \\
\hline 16-20 weeks & 47 & 18.58 & 1.16 & 0.819 \\
\hline$>20-24$ weeks & 34 & 21.41 & 1.89 & 0.862 \\
\hline$>24-28$ weeks & 15 & 28.62 & 3.06 & 0.963 \\
\hline$>28-32$ weeks & 25 & 39.14 & 3.15 & 0.600 \\
\hline$>32-36$ weeks & 67 & 44.72 & 2.72 & 0.376 \\
\hline$>36-40$ weeks & 12 & 49.72 & 2.41 & 0.398 \\
\hline Overall & 200 & 33.01 & 12.12 & 0.984 \\
\hline
\end{tabular}

Table 4: correlation of gestational age (by LMP) by estimated gestational age based on TCD (using linear equation derived in the study).

\begin{tabular}{|c|c|c|c|c|c|c|c|c|c|}
\hline \multirow{2}{*}{$\begin{array}{l}\text { Gestational } \\
\text { age (weeks) by } \\
\text { LMP (weeks) }\end{array}$} & \multicolumn{2}{|c|}{$\begin{array}{l}\text { GA by LMP } \\
\text { (weeks) }\end{array}$} & \multirow{2}{*}{$\begin{array}{l}\text { GA by } \\
\text { TCD } \\
\text { (weeks) } \\
\text { Mean }\end{array}$} & \multicolumn{3}{|c|}{$\begin{array}{l}\text { Estimated- } \\
\text { actual (weeks) }\end{array}$} & \multicolumn{2}{|c|}{$\begin{array}{l}\text { Significance of difference } \\
\text { (Paired ' } t \text { '-test) }\end{array}$} & \multirow{2}{*}{$\begin{array}{l}\text { Correlation } \\
\text { between actual } \\
\text { and estimated GA } \\
\text { 'r' }\end{array}$} \\
\hline & Mean & SD & & SD & Mean & SD & ' $t$ ' & 'p' & \\
\hline $16-20(n=47)$ & 18.81 & 0.99 & 19.49 & 0.63 & -0.69 & 0.59 & -7.91 & 0.000 & 0.82 \\
\hline$>20-24(\mathrm{n}=34)$ & 21.42 & 1.32 & 21.04 & 1.03 & 0.38 & 0.67 & 3.24 & 0.003 & 0.86 \\
\hline$>24-28(\mathrm{n}=15)$ & 25.94 & 1.16 & 24.99 & 1.67 & 0.96 & 0.64 & 5.81 & 0.000 & 0.96 \\
\hline$>28-32(\mathrm{n}=25)$ & 30.93 & 0.96 & 30.74 & 1.72 & 0.19 & 1.38 & 0.68 & 0.505 & 0.60 \\
\hline$>32-36(\mathrm{n}=67)$ & 33.72 & 0.97 & 33.79 & 1.49 & -0.07 & 1.44 & -0.40 & 0.693 & 0.38 \\
\hline$>36-40(\mathrm{n}=12)$ & 37.02 & 0.78 & 36.53 & 1.32 & 0.50 & 1.24 & 1.39 & 0.192 & 0.40 \\
\hline Total & 27.391 & 6.74 & 27.386 & 6.63 & -0.004 & 1.19 & 0.052 & 0.959 & 0.984 \\
\hline
\end{tabular}

\section{DISCUSSION}

Estimation of gestational age in the pregnancies without accurate last menstrual period information is a daunting task for sinologist, especially in case of growth restricted pregnancies. Although for normal pregnancy fetal or maternal biometric parameters are helpful for the estimation of gestational age as successive growth of these parameters during the course of pregnancy helps to identify the gestational age, however, in case of growth restricted pregnancies, the fetal growth is often impaired and fails to match with the progression of pregnancy. In such a case, estimation of gestational age is difficult more so in case of missing LMP information.

Hence, the focus of a sonologist is generally on such parameters that can be used independently without being affected by the impaired growth of the fetus. In recent years, tricerebellar diameter has been identified as a useful growth indicator that sustains the growth pattern irrespective of the overall growth pattern of pregnancy. In present study we used this method to predict the gestational age in normal and IUGR affected pregnancies.

For this purpose, a total of 200 consecutive pregnant women aged 18 to 43 years with mean age 26.79 years were enrolled in the study. Compared to another study from India, the present study had a higher mean maternal age. In a study done by Prasad and Likhitha, they reported the mean maternal age as 21.79 years. ${ }^{4}$ Lower age pregnancy and motherhood are generally associated with lower socioeconomic strata and less educated subsets of population. However, the fact that present study was carried out in a hospital that caters specifically to govt employees and their dependents, who are socioeconomically better as compared to general population and at the same time have a higher literacy rate. Similar to findings of present study, Fatima et al who also conducted their study in a military hospital in Pakistan also reported the mean maternal age to be comparable to present study at 26.80 years. ${ }^{5}$

In present study, women were enrolled in second and third trimesters starting from 15 weeks 6 days to 38 weeks 2 days. Mean gestational age was 27.39+6.74 years. Maximum number of women in present study were in 32-36 weeks of pregnancy (33.5\%). In different studies reviewed by us the gestational age of women has shown a considerable variability depending on the criteria of enrolment. Bansal et al, in their study enrolled the women starting from gestational age 14 weeks to 38 weeks with women in 32-36 weeks of pregnancy comprising $<25 \%$ of total cases. ${ }^{6}$ However, Gupta et al in their study enrolled women with gestational age varying from 14 to 40 weeks and had maximum proportion of women $(42.8 \%)$ in gestational age $35-40$ weeks. ${ }^{7}$ Contrary to this, Garg et al in their study enrolled only second trimester pregnancies with gestational age varying from 14 to 26 weeks. ${ }^{8}$ The fact that present study was carried out in a referral hospital, where pregnant women are often 
referred for delivery from the respective primary care centres and hence the higher proportion of women with near term gestational age is reflective of the profile of pregnant women availing our facility.

In present study, the IUGR detection rate was $13 \%$ and it was based on clinical suspicion. In different studies, the IUGR detection rate has been shown to vary substantially, depending upon the screening criteria used. Bansal et al in their study had an IUGR detection rate of $9.2 \%$ using a criterion similar to ours. ${ }^{6}$ Malik et al however in their study used a USG prediction model and calculated the IUGR rate as $10 \% .{ }^{9}$ Prasad and Likhitha, on the other hand in their study reported an IUGR rate of $20 \%$ for their study conducted in third trimester pregnancies. $^{4}$ In fact, in present study, out of total 26 IUGR cases diagnosed, $76.9 \%$ were in pregnancies with gestational age $>28$ weeks. The fact that clinical suspicion of IUGR is dependent on the gestational age and that is why there are higher proportion of IUGR cases in studies conducted specifically in third trimester pregnancies as well as in third trimester pregnancies in present study.

In present study, for different gestational ages, gestational age estimates for biometric parameters (BPD, AC, FL and composite GA) showed a progressive trend. For biparietal diameter, mean difference from actual gestational age showed a variability of $0.07+0.59$ weeks (16-20 weeks) to $-1.75 \pm 1.32$ weeks and an overall difference of $-0.18 \pm 1.34$ weeks. On comparing the difference between actual gestational age and estimated gestational age, the difference was non-significant for overall and other gestational age groups except for 36-40 weeks where the difference was significant statistically. In fact, biparietal diameter estimates are often affected in IUGR pregnancies and that is why the gestational age group with maximum prevalence of IUGR $(50 \%)$ had shown a high variability from the actual estimates. As far as accuracy of BPD in assessment of gestational age is concerned, it was generally consistent with actual gestational age and overall estimates showed a near perfect $(r=0.98)$ correlation between actual and estimated age. The precision of BPD in normal pregnancies is wellestablished as revealed by different studies in the past too. ${ }^{8,10,11}$ For other parameters like AC and FL as well as for composite gestational age calculation too, the consistency level between actual gestational age and estimated gestational age was not that good as for BPD. For all these estimates, for overall estimates, the mean difference in actual gestational age and estimated gestational age was significant statistically. However, for TCD, we obtained high correlation between actual and gestational age for overall estimation $(\mathrm{r}=0.98)$ as well as a strong to moderate correlation $(r>0.5)$ for gestational age groups starting from 16 weeks to 28 weeks. Thus, helping us to derive a linear regression equation for the estimation of gestational age which found TCD as a strong and significant estimator of gestational age. Similar to present study, Bansal et al in their study also found this relationship to be of use and generated a regression equation. ${ }^{6}$ Gupta et al also derived a similar equation for gestational age estimation while Goel et al derived a relationship between gestational age as an independent predictor of TCD to highlight the applicability of this relationship when looked back too.,12 Similar relationship models were developed by other workers too and found that TCD is a strong estimator of gestational age. On reviewing the contemporary literature too, we found that in several studies comparing multiple fetal biometric parameters, although BPD and TCD have emerged as good predictors of gestational age at most of the gestational age groups as well as overall estimation, the case is not so for other parameters. ${ }^{13}$ Luiz et al.in their study found TCD to be more consistent with gestational age as compared to other biometric parameters. ${ }^{14}$ However, contrary to results of present study, Papageorghiou et al. in their study found HC and FL to be better predictors of gestational age as compared to BPD. ${ }^{15}$ However, their study differs from present study owing to its limitation of being conducted in second trimester pregnancies, moreover, they also did not specify whether the study was carried out in normal pregnancy or had included the pregnancies with IUGR as done in present study. Similar to present study, Uikey et al and Prasad and Likitha similar to present study found BPD and TCD to be better predictors of gestational age as compared to other fetal biometric parameters. ${ }^{4,16}$

In present study, difference in estimated and actual gestational ages as estimated by TCD were more precise for third trimester $>28$ weeks as compared to those in 1628 weeks of pregnancy, however, overall estimates strongly correlated with actual gestational age $(r=0.984)$ and thus showed statistically no significant difference between actual and estimated age. Thus, for third trimester pregnancy, TCD was found to be a better predictor of gestational age in a pregnancy having combination of both normal as well as IUGR cases. However, another study, highlighted its role in both second as well as third trimester pregnancies. ${ }^{17}$ The findings in present study, in turn endorse the observation of Naseem et al Contrary to findings of present study, Chavez et al found TCD to be a better predictor of gestational age in second trimester as compared to third trimester pregnancies. ${ }^{18,19}$ The findings in general thus found that TCD is a useful predictor of gestational age than most of the other biometric parameters being assessed.

However, the present study highlighted the usefulness of TCD in context of its utility in precise estimation of gestational age irrespective of it being affected by growth restriction. In present study, the difference between actual and estimated gestational age between normal and IUGR pregnancies for different biometric parameters showed that except for TCD, all the other estimators had significantly underestimated the gestational age for IUGR pregnancies whereas TCD did not show a variability in estimates for gestational age for both IUGR as well as 
normal pregnancy thus establishing its role as an accurate predictor of gestational age irrespective of the growth status of the fetus while at the same time showed that although TCD cannot be a good predictor for estimation of intrauterine growth and hence must be viewed as a precise estimate for gestational age assessment only. This finding has a practical usefulness as it provides a basis to utilize the normogram estimate values for dating the pregnancies in which LMP is unknown. Similar to findings of present study, the role of TCD in prediction of accurate gestational age in normal as well as IUGR pregnancies has also been highlighted in several previous studies too. $6,9,19$

Thus, being a stable parameter irrespective of growth status of festus, provides a basis for its usefulness as a ratio to predict IUGR and other perainatal outcomes as used in several studies. ${ }^{20,21}$

\section{CONCLUSION}

Thus, despite not being a direct marker for IUGR it can serve as a surrogate marker for detection of IUGR and another adverse perinatal outcome. The findings of present study were thus enlightening, provided useful information and establish TCD as an independent reliable marker for estimation of gestational age in both normal and IUGR pregnancies.

Funding: No funding sources

Conflict of interest: None declared

Ethical approval: The study was approved by the Institutional Ethics Committee

\section{REFERENCES}

1. Caughey AB, Nicholson JM, Washington AE. Firstvs second-trimester ultrasound: the effect on pregnancy dating and perinatal outcomes. Am J Obstet Gynecol. 2008;198(6):703-5.

2. Araujo EJ, Pires CR, Nardozza LM. Correlation of the fetal cerebellar volume with other fetal growth indices by three-dimensional ultrasound. J Matern Fetal Neonat Med 2007; 20(8):581-7.

3. Chavez MR, Ananth CV, Smulian JC, Yeo L, Oyelese Y, Vintzileo AM. Fetal transcerebellar diameter measurement with particular emphasis in the third trimester: a reliable predictor of gestational age. Am J Obstet Gynecol 2004; 191(3):979-84.

4. Satish Prasad BS, Likhitha S. Cerebellar Measurements with Ultrasonography in the Evaluation of Fetal Age. IOSR Journal of Dental and Medical Sciences (IOSR-JDMS).2014; 13(9):49-56.

5. Fatima K, Shahid R, Virk A. Determination of mean fetal transcerebellar diameter as a predictive biometric parameter in third trimester of pregnancy in correlation with fetal gestational age. Pak Armed Forces Med J. 2017; 67(1):155-60.

6. Bansal M, Bansal A, Jain S, Khare S, Ghai R. A study of Correlation of Transverse Cerebellar
Diameter with Gestational Age in the Normal \& Growth Restricted Fetuses in Western Uttar Pradesh. People's J Sci Res. 2014;7(2):16-21.

7. Gupta AD, Banerjee A, Rammurthy N, Revati P, Jose J, Karak $\mathrm{P}$ et al. Gestational age estimation using transcerebellar diameter with grading of fetal cerebellar growth. Nat J Clinical Anat. 2012;1(3):115-120.

8. Garg A, Pathak N, Gorea RK, Mohan P. Ultrasonographical Age Estimation from Fetal Biparietal Diameter. J Indian Acad Forensic Med. 2010;32(4):308-310.

9. Malik R, Pandya V K, Shrivastava P. Gestational age estimation using transcerebellar diameter with grading of fetal cerebellum and evaluation of TCD/AC (Transcerebellar diameter/abdominal circumference) ratio as a gestational age independent parameter. Indian J Radiol Imaging. 2003;13(1):957.

10. Taipale P and Hiilesmaa V. Predicting Delivery Date by Ultrasound and Last Menstrual Period in Early Gestation. Obstet Gynecol. 2001;97(2):189-94.

11. Gameraddin M, Alhaj B, Alabdeen MZ. The Reliability of Biparietal Diameter and Femoral Length in Estimation the Gestational Age Using Ultrasonography. J Gynecol Obstet.2014;2(6):112-5.

12. Goel P, Singla M, Ghai R, Jain S, Budhiraja V, Rameshbabu CS. Transverse cerebellar diameter - a marker for estimation of gestational age. J. Anat. Soc. India 2010;59(2):158-61.

13. Davies MW, Swaminathan $M$ and Betheras FR. Measurement of the transverse cerebellar diameter in preterm neonates and its use in assessment of gestational age. Austral Radiol. 2001;45(3);309-12.

14. Luiz N, Fernandes MA and Luiz K Jr. Ultrasonographic Evaluation of Fetal Growth with the use of the Transverse Cerebellar Diameter. Rev. Bras. Ginecol. Obstet. 2000;22(5):281-6.

15. Papageorghiou AT, Kemp B, Stones W, Ohuma EO, Kennedy SH, Purwar M, et al. Ultrasound Based gestational-age estimation in late pregnancy. Ultrasound Obstet Gynecol. 2016;48(6):719-26.

16. Uikey PA, Kedar KV, Khandale SN. Role of transcerebellar diameter in estimating gestational age in second and third trimester of pregnancy. International Journal of Reproduct, Contracep, Obstet Gynecol. 2016;5(10):3411-5.

17. Mahmoud MZ, Mahmoud OA and Abdulla AA. Fetal Transverse Cerebellar Diameter Measurement for Prediction of Gestational Age in Pregnant Sudanese Ladies. Int $J$ Life Sci Med Res. 2013;31(3):89-93.

18. Naseem F, Fatima N, Yasmeen S and Saleem S. Comparison Between Transcerebellar Diameter with Biparietal Diameter of Ultrasound for Gestational Age Measurement in Third Trimester of Pregnancy. J Coll Physicians Surg Pak. 2013;23(5):322-5.

19. Chavez MR, Ananth CV, Smulian JC, Vintzileas AM. Fetal Transcerebellar Diameter Measurement 
for Prediction of Gestational Age at the Extremes of Fetal Growth. J Ultrasound Med 2007;26(9):116771.

20. Vinkesteijn, Mulder PG, Wladimiroff JW. Fetal transverse cerebellar diameter measurements in normal and reduced fetal growth. ultrasound Obst Gynaecol. 2000;15(1):47-51.

21. Dhumale H, Pujar YV, Shravage JC, Bellad MB, Sherigar BY, Durdi GS, Amber SS. Fetal Transcerebellar Diameter to Abdominal Circumference Ratio (TCD/AC) in the Assessment of Normal Fetal Growth Donald School J Ultrasound Obstet Gynecol, 2010;4(4):455-7.

Cite this article as: Dashottar S, Senger KPS, Shukla Y, Singh A, Sharma S. Transcerebellar diameter: an effective tool in predicting gestational age in normal and IUGR pregnancy. Int J Reprod Contracept Obstet Gynecol 2018;7:4190-6. 